\title{
Teaching to Transgress: Subjective Educational Experience in the Model of Engaged Pedagogy of Bell Hooks (Gloria Jean Watkins)
}

\section{KEYWORDS}

bell hooks, engaged pedagogy, critical pedagogy, feminism, subjective experience

\begin{abstract}
The African-American scholar bell hooks is a well known figure in the Western academic milieu. This article makes an attempt at presenting the model of engaged pedagogy represented in hook's works and her public appearances. This is done by highlighting the issue of subjective experience in the educational setting. Hook's concept of race and gender is brought to attention to present the aforementioned issue within the broader context of her socio-cultural concepts she is known for. The outcome of this reconstruction shows us that the model of engaged pedagogy is developed by hooks into a wide set of postulates of structural change of the American schooling system, as well systems in other parts of the world. Therefore, it seems plausible to put her works within the tradition of critical pedagogy as found in the works of Paulo Freire and others.
\end{abstract}

Adam Mickiewicz University Press, pp. 7-16

ISSN 2300-0422. DOI 10.14746/kse.2019.15.1

ORCID: https://orcid.org/0000-0003-1060-6324

\section{Introduction}

Today, the figure of bell hooks is known in the intellectual world primarily on account of her exceptional engagement in the political and social consequences of the American reality and the racial relations underlying this reality. Nevertheless, it must be remembered that hook's impact on the American public debate cannot be overestimated if we take into account the fact that the problems tackled by 
her most often go beyond the racial discourse, also touching upon a number of other issues of equal importance for the American society. Located in the formula of a "public intellectual", hooks often performs a detailed analysis of racial relations resulting from social tension typical for the situation in the United States and transfers them to the area of the discussion on the role which the concept of race plays in the processes of reproducing specific social structures. A characteristic feature of these structures is appropriation of the field of the subject for the sake of progressing instrumentalisation of human acts, motivation and style, in which individuals usually express their subjective desires and identity. The place that the category of race occupies in these processes is, in the opinion of the American author, of key importance for understanding how subjects act in the social environment filled with mechanisms for solidifying and transmitting specific inequalities. This category is also supplemented by other significant social concepts such as, e.g., gender. This puts hooks in the position of a researcher located in the area of feminist criticism related to the third wave of intellectual evolution of this formation and, more specifically, among the authors from the realm of the so-called "black feminism."

Born in 1952 in Hopkinsville (Kentucky) as Gloria Jean Watkins, the researcher adopted the pseudonym bell hooks (intentionally written in lower-case letters for the purpose of conscious subversion of the principles of Western grammar) in reference to the context of her family history (her grandmother's name was Bell Hooks and she was notorious for openly expressing her uncompromising opinions). It was also meant to reflect her working origin by suggesting anonymity and universality of life experience of her own, as well as many other African-Americans from similar social backgrounds. Analogously to many other African-Americans, she experienced segregation in the school system, attending a facility dominated by pupils from the white middle class. The problem of inequalities between the white majority and minorities such as African-Americans affected the overall academic accomplishments of hooks. However, at the turn of the 1970s and 1980s, this field was not well managed. Her research interest in the racial issues initially resulted from frustration caused by the fact that few white scientists where interested in this subject matter back then (hooks, 2000, p. 2). The special feeling of the necessity of filling the racial discourse with a perspective originating from the perspective of an African-American author pervaded, as hooks admits, her intellectual activity and affected her later steps and searches in the area of academic knowledge. It was also the time when her critical sense was shaped, along with the political stance, often expressed today. In this place, it must be noted that academic writing, political activism and life are, for hooks, inseparable aspects of the same 
cultural reality. Hooks recollects after several years: "As a leftist cultural activist, I work to think and write critically in a manner that clearly indicates specific strategies for radical or revolutionary interventions that I apply in daily life to oppose the policy of domination" (hooks, 2000, p. 7). When starting her university career in 1976 at the University of Southern California, hooks initially taught English literature and ethnic studies. Since that moment, she has held a number of various academic positions, inter alia as part of Afro-American Studies and English Literature at the University of Yale, women's studies and American literature at Oberlin College in Ohio, as well as the Faculty of English Literature at City College in New York. Since 2004, she has been working at Berea College in Kentucky at the position of a professor in residence as part of the Faculty of Appalachian Studies ${ }^{1}$. She also continues her studies on relations between the categories of gender and socio-cultural factors, such as the various constructs of the term race. Social constructivism is characteristic for the theory of gender and the concept of race formulated by hooks, even though it is not the exclusive interpretation for the critical thought of the author.

\section{Outline of Feminist Theory in Bell Hook's Approach}

It is worth remembering that the feminist theory of hooks is not only related to the essentially understood category of womanhood and gender. In the text entitled "Theory as Liberatory Practice" of 1991, she expresses her interest in any kind of socio-cultural category whose effect of formulation would be a critical, in its nature, inspection of actual dependencies and relations of power relying on gender categories (hooks, 1991, p. 1). These dependencies may also entangle the academic practice and have their reflection in the manner in which the feminist thought and other critical forms clash with the hegemony of the patriarchal system or the situation of white domination, typical for the United States. The American thinker looks for the cause of this state of affairs in the durable rooting of certain rhetorical conventions in the academic world. These conventions are generated as part of specific orders, where models designed by the dominant majority (in the American practice, white) are predominant. Language, as well as the feminist rhetoric, is frequently appropriated, in her belief, by groups not representing interests or not sharing the same experience of marginalisation as ethnic minorities, women or other groups affected by hegemonic and more or less oppressive, power. The

\footnotetext{
${ }^{1}$ http://www.theheroinecollective.com/bell-hooks/
} 
American feminism of the 1980s did not represent the voice of African-American women in a significant degree. Giving them voice and a change in the discourse seemed, from this perspective, not only a necessary step towards the transformation of the feminist theory, but also a political necessity. This change also affected the rhetoric and the linguistic area producing the conceptual base for the theory of gender. Hooks notes: "Critical reflection on contemporary production of feminist theory makes it apparent that the shift from early conceptualisations of feminist theory (which insisted that it was most vital when it encouraged and enabled feminist practice) begins to occur or at least becomes most obvious with the segregation and institutionalisation of the feminist theorising process in the academy, with the privileging of written feminist thought/ theory over oral narratives" (hooks, 1991, p. 3). Therefore, the manifestation of postulates of African-American feminism (or rather feminism not proper to white women) requires a look at other forms of speech, linguistic practice and rhetoric than exclusively characteristic for the academic discourse. Such intention explains to a significant degree why the language used by hooks both in her works and in public appearances is far from intellectual elitism, and much closer to the modes of expression typical for lower social classes. Her version of feminist theory is an "experienced" theory, close to life.

In her canonical text with respect to the bases of feminist theory of 1984 entitled "Feminist Theory: From Margin to Center", hooks voices a conviction that "feminism in the United States has never emerged from the women who are most victimised by sexist oppression" (hooks, 1984, p. 1). This means that, in fact, the feminist theory missed its object of reference in the social sense. This state of affairs has been solidified by a significant portion of early literature on the subject, including the works of Betty Friedan and Leah Fritz. Hooks negatively assesses the possibilities of impact of theoretical proposals of this type. This results from the fact that these are primarily non-white women who constitute, in her opinion, the "silent majority", representing the most blatantly visible social, political and economic symptoms of actual marginalisation. Therefore, shifting the point of balance in the discussion about inequalities towards particular contexts greatly diversifying the problem of discrimination allows for precise specification of the status aspect and enables a closer look at various forms of marginalisation of women from different social and ethnic groups in a given social system. Opening of new areas of theoretical and subject-related searches is the task of feminist thought. Hooks clearly expresses this idea by saying that: "We resist hegemonic domination of feminist thought by insisting that it is a theory in the making, that we must necessarily criticise, question, re-examine and explore new possibilities" (hooks, 1984a, p. 10). Such presentation of the issue allows for showing the situation of women not only 
in the light of their dependency on the dominant patriarchal status quo, but also as a part of a broader social movement focused on challenging and healing the relations relying on the concept of gender or race. A highly postulative dimension of ideas presented by hooks may slightly overshadow her overall theoretical intention. Therefore, the theoretical foundation should be specified in detail here.

In another place, hooks presents a clear interpretation of feminism. In her opinion, it is a movement opposing the phenomenon of sexism (hooks, 1984b, p. 24). This step towards emphasising the performative nature of feminist theory, important from the definition-based point of view, specifies further consequences of its utilisation in the social realm. Nevertheless, application of postulates of feminist movement encounters significant problems. First of all, as noted by hooks, the movement is neither a uniform or a formalised phenomenon in the sense of political activism. Thus, it is devoid of a sensible form, and the feminist postulates frequently differ among one another apart from one basic premise: equality of women and men. In hooks' belief, this postulate is the most problematic. Its explication assumes that even though inequalities exist between the status of women and men, yet they are based on similar initial conditions as far as the inferior role of women with respect to men is concerned. Obviously, this is an unjustified generalisation and a basic error of the second wave feminism. According to hooks, these relations are not only much more complex, but they overshadow the core of the problem, i.e. the conviction rooted in the social order that categories of gender do not overlap with racial categories. For hooks, the position of black women in the American context is radically different than the position of women from white middle or working class. This quite evident difference in status results from durably rooted socio-cultural discourses, where the African-American population is usually placed at the bottom of the social ladder. Representations of being black (blackness) remain rooted in the structures of power and are continually subjected to the mechanisms of marginalisation of black culture. Therefore, oppression by the white majority reveals its power in the construction and perpetuation of cultural notions thanks to which black subjects are objectified, whereas the black culture is instrumentally used (the phenomenon of the so-called cultural appropriation). Hence, it seems even more necessary to invoke social protest and movement against racism and chauvinism. In this case, the feminist theory moves closer to the political activism, yet it does not lose its epistemological nature, which is important for the formulation of the concept of gender and race. It rather suggests the necessity of building a certain formula of common identity, meeting any types of oppression.

In this place, attention should be paid to the sisterhood concept constructed by hooks. She notices that "the utopian vision of sisterhood evoked in a feminist 
movement that initially did not take racial difference or anti-racist struggle seriously did not capture the imagination of most black women/women of colour" (hooks, 2000b, p. 56). Hence, sisterhood in this approach is a bond among women from various social groups, beyond class divisions, yet at the same time aware of the fact how different the subordinate position of women with respect to men may be from the point of view of women who originate from various groups. Such an impression of a transgressive relation between women must be, in hooks' conviction, deep and reject any false forms of common identity (hooks, 1984, p. 45). It must also contribute to the reformulation of the feminist theory and lead to the establishment of a new, more visionary feminism. Its fundamental goal is to work out a strategy of change of the entire mass of women and to solidify their personal power (hooks, 200b, p. 111). Sisterly identity allows for combining the actions and goals into more sensible and more efficient, with respect to social and political aspects, postulates for transformation of structures of power and abolishing the tools of oppression, both on the side of men, as well as class and racial oppression. Visionary feminism postulated by hooks is not only limited to women. It refers to any inequalities and thus may be also be referred to the situation of subordination of men in specific social contexts. And thus, the alliance of women and men who are in the same status position may not only be actually established, but also seems to be socially indispensable in the world where the problem of inequality is alarmingly growing. Hooks emphasises this in an interview with Cornel West by saying that the partnership of women and men in the 1990s may result in an extension of the feeling of rooting and also solidify the mechanisms which, actually, abolish the power of structures marginalising either African-Americans or other minority groups (hooks, bell, 1990, p. 214). In other words, the alliance is meant to guarantee the possibility of giving voice to those whom Frantz Fanon calls the "cursed people of the earth." Subjectivisation is conditioned by the educational effort for the sake of proliferation of subjective awareness and critical stances. Thanks to them, it is possible to change the social formula of understanding the relation between gender and race and, in a further perspective, also abolish the structural oppression.

\section{Towards Transgressive and Engaged Pedagogy}

Hooks identifies the role of education in the process of liberating an entity with an effect accomplished via educational practice. In her work "Teaching to Transgress. Education as the Practice of Freedom" from 1994, we find a systemic interpreta- 
tion of the theory of a subject, kept in the spirit of a critical reflection on the condition of modern education and the American society. Hooks indicates the fact that the book is, in her conviction, primarily a collection of testimonies for the sake of education as a mode of practising freedom, due to the fact that education as such is, in the first place, a performative act (hooks, 1994, p. 11). School reality provides numerous pieces of evidence for such statement. Complex relations along the line students - teachers require application of the model of engaged pedagogy, whose transformative potential with respect to the systems of education lies in it fostering the subjective experience. In any case, hooks is not alone in her conviction.

The formula of engaged pedagogy is related to the problem of subjective experience of the system of education, and thus forces us to take a look at the strategies of acting that are adopted by individuals when clashing with the school institution. Kris D. Guttiérez and Barbara Rogoff believe that the key for the understanding of the subject's acts in the educational reality is the issue of cultural ways of learning. This is a relatively new theoretical perspective and "the cultural styles approach arose from these efforts as researchers attempted to leave behind deficit-model thinking, in which cultural ways that differ from the practices of dominant groups are judged to be less adequate without examining them from the perspective of the community's participants" (Guttiérez, Rogoff, 2010, p.184). Revealing a great variety of the above-mentioned styles in the school space does not pose greater problems, in particular in contexts of multi-cultural societies, such as the American society. School, as an institution, is pervaded with multiple learning and teaching strategies. Nevertheless, individual and subjective approach of the teacher towards students is neither a common nor acceptable principle on the systemic level. Hence, the attempts at breaking the petrified and institutional standards seem even more precious; they not only excite interest in students, but also personally empower them and lead to formation of certain intellectual maturity. Cultural differences that become visible during the teaching processes cannot be examined as individual subjective features, because - as suggested by Guttiérez and Rogoff - this leads most often to the formulation of unauthorised generalisations and, in turn, they contribute to the formation of classification and categorisation systems, "yielding explanations and expectations of individual skills and behaviours on the basis of category membership" (Guttiérez, Rogoff, 2010, p. 187).

Taking the social and cultural differences into account in the process of learning is a task set directly before the engaged pedagogy. It is meant to contribute to such a change in the system of teaching and educational practice to make the subjective educational experience consistent both with the horizon designated by the individual and group identity (if we speak about, e.g., self-identification in a cul- 
tural sense). Such approach allows for much better and fuller use of the individual's educational potential and reinforces the feeling of purpose, internal integration on the level of self-awareness and desire for social engagement. This task is, by no means, easy; hooks is convinced that "progressive, comprehensive education, engaged pedagogy" is more demanding than a conventional critical thought or feminist pedagogy. As opposed to these two practices of teaching, she emphasises the problem of "well-being" (hooks, 1994, p. 15). Therefore, the pedagogical goal is such relational feedback which does not disrupt the subjective feeling of causality and fosters creative development. This means that the teachers must be authentically engaged in the sense of actual practice in the process of self-determination of the subject of teaching. This process should promote the well-being of individuals, i.e. linearly harmonise with their internally recognised condition of psychical, social and cultural homoeostasis. Hooks compares efficient pedagogical activities to therapeutic sessions (hooks, 1994, p. 15). In the engaged perspective, the moment of acknowledging a subject determines its positioning in a multi-dimensional reality, where every dimension (psychological, political or cultural) gives the subject the possibility of articulating needs or specific ontological statements resulting from the world-view represented by such subject. Recognizing a subject in the pedagogical practice is, therefore, tantamount to the subject's co-participation in the educational process. What is more, it also does away with the traditional division of acting in a public and private sphere, wholly pervading the area of social relations and interactions. In the perspective of engaged pedagogy, a school becomes a field where diverse learning styles and living styles clash, providing ethnographic exemplifications for the fact of cultural diversity, even in systems considered relatively homogeneous.

\section{Subjective Educational Experience and Process of Transgressive Community Construction}

A subjective educational experience in the model of bell hook's engaged pedagogy is a problem with central significance for the concept of race and theory of teaching performed in a multi-cultural reality, represented by this author. Discrimination experiences of many African-Americans in the American system of education still constitute a significant factor in the structural marginalisation of this group within the structures of American society. As evidenced by recent racial unrest, the situation in the USA with respect to the relation of power between the white majority and the minorities is characterised, to a great extent, by maintenance of the status 
quo. The system of education, similarly to many other dimensions of the American public sphere, requires an in-depth transformation for the sake of education liberating through empathy and action, affective in their nature. As noted by Michael J. Monahan, education for hooks is not identical with the process of information accumulation (Monahan, 2011, p. 107). It is rather a set of practices that either may enslave the subject or thrust the subject into a pre-defined framework, which results in its' instrumentalisation and spreading of violence, or such practice may emancipate the subject and contribute to an increase in the level of the above-mentioned well-being. In this perspective, the systemic change depends on the grassroots activities undertaken by teachers in reference to students. In particular, such activities should be focused on students who originate from these groups that are underprivileged in a given educational and social system, or even marginalised and subjected to various forms of discrimination. However, the vision of education as emancipatory struggle is a picture full of axiological challenges for hooks.

In "Teaching to Transgress", hooks postulates initiation of a revolution in the sphere of values (hooks, 1994, p. 28). Such revolution, in the intention of the American author, is meant to enable such life where differences are not only perceived in the political sense, but also in a dimension of moral recognition of the rights of others to self-determination. Such a procedure of axiological diversification creates a possibility of actual cultural differentiation in the educational space. It allows for inclusive teaching, i.e. including the subjects in the process of education, not only in the sense of their presence in the system of teaching, but together with the knowledge, meanings and modes of communication contributed by them. This makes the school reality democratic, where hooks sees an important pedagogical value. This means that it is necessary to "[make] the classroom a democratic setting where everyone feels a responsibility to contribute," and this "is a central goal of transformative pedagogy" (hooks, 1994, p. 39). The presence of a subject marked with racial, gender or cultural differences contributes not so much to the dynamisation of the system of education, but more to the initiation of a vital reform in it. Thanks to it, inclusion in the educational narrative of various visions and world views becomes possible and, through this, also learning styles and styles of acquiring new competence. By opening to the subjective educational experience, the process of education acquires a shape that allows for modelling the system of education in a material manner, along with the trajectory of the changing reality. The tool forming this approach is the engaged pedagogy and a critical approach.

In her pedagogical model, hooks not only uses, but also openly refers to earlier attempts at applying the complex postulates tackled by Paulo Freire. The Brazilian teacher is an inspiration and, at the same time, an ideological source for hooks. 
Opinions voiced by Henry Giroux and Peter McLaren are also close to her. However, it cannot be stated straightforwardly that all of these authors create a uniform concept formation and share, together with hooks, her ideas about race and gender. Nevertheless, hooks shows a number of convergences with the American critical pedagogy represented by them. She concludes that issues tackled by all critical teachers must primarily focus on the problems of permeation of power, action and struggle (hooks, 1994, p. 129). Tackling the problem of infiltration of these aspects also requires raising the need of internal dialogue and critical reflection on the hitherto applied solutions, existing socio-cultural, economic and political conditions in the teaching milieus. The process of building a "teaching community" is close to her sisterhood concept. The transgressive community also encompasses entities experiencing various systems of education, not only educational decision-makers and teachers. The model of engaged pedagogy represented by bell hooks clearly indicates the huge value carried by education that includes the subjective experience in the official educational and social discourse. Thanks to such conceptual measure, working out new and much more efficient models of education becomes possible.

\section{Bibliography}

Freire Paulo, Pedagogy of the Oppressed, New York, London 2010, Continuum Press.

hooks bell, Teaching to Transgress: Education as the Practice of Freedom, New York, London 1994, Routledge.

hooks bell, Feminism is for Everybody. Passionate Politics, Cambridge 2000, South End Press.

hooks bell, Theory as Liberatory Practice, [in:] Yale Journal of Law and Feminism, vol. 4, Issue 1, 1991,

pp. 1-12.

hooks bell, Feminist Theory - From Margin to Center, Boston 1984, South End Press.

hooks bell, Talking Back: Thinking Feminist, Thinking Black, Boston 1989, South End Press.

hooks bell, Where We Stand: Class Matters, New York, London 2000, Routledge.

bell hooks, Black Looks: Race and Representation, Boston 1992, South End Press.

Monahan Michael J., Emancipatory Effect: bell hooks on Love and Liberation, [in:] CRL James Journal, Vol. 17, No. 1, 2011, pp. 102-111.

Sevilla Anton Louis, The Ethics of Engaged Pedagogy: A Comparative Study of Watsuji Tetsuro and bell hooks, [in:] Kritike, Vol. 10, No. 1, 2016, pp. 124-145. 